\title{
Salmonella enterica and extended-spectrum cephalosporin-resistant Escherichia coli recovered from Holstein dairy calves from 8 farms in New Brunswick, Canada
}

\author{
Babafela Awosile, ${ }^{* 1}$ J. McClure, ${ }^{*}$ Javier Sanchez, ${ }^{*}$ Juan Carlos Rodriguez-Lecompte,† Greg Keefe, ${ }^{*}$ \\ and Luke C. Heider* \\ *Department of Health Management, and \\ †Department of Pathology and Microbiology, Atlantic Veterinary College, University of Prince Edward Island, Charlottetown, PE, C1A 4P3, \\ Canada
}

\begin{abstract}
This study was carried out to determine the frequency of fecal carriage, antimicrobial susceptibility, and resistance genes in Salmonella enterica and Escherichia coli with reduced susceptibility to extended-spectrum cephalosporins (ESC) isolated from 488 dairy calves from 8 farms in New Brunswick, Canada. Both S. enterica and E. coli with reduced susceptibility to ESC were isolated using selective culture. Minimum inhibitory concentrations to a panel of antimicrobial drugs were determined for randomly selected $E$. coli isolates and all of the Salmonella isolates. Multiplex PCR were conducted on the selected ESC-resistant $E$. coli to assess the $\beta$-lactamase resistance genes ( $b l a_{\mathrm{CTX-M}}, b l a_{\mathrm{CMY}-2}$, $b l a_{\mathrm{SHV}}$, and $\left.b l a_{\mathrm{TEM}}\right)$ and plasmid-mediated $q n r B$ and $q n r S$ resistant genes. Information on ceftiofur use and other farm management practices were collected by the use of a questionnaire to determine the risk factors for the fecal recovery of $E$. coli with reduced susceptibility to ESC. Salmonella enterica frequency in calves' fecal samples was $3.3 \%$, and all were pansusceptible. Salmonella isolates belonged to 3 serovars namely Salmonella Senftenberg, Salmonella Typhimurium, and Salmonella Derby. The frequency of fecal carriage of E. coli with reduced susceptibility to ESC in calves was $81.2 \%$. Of the selected isolates $(\mathrm{n}=100)$, all were multi-drug resistant, whereas $88 \%$ were ESC resistant based on minimum inhibitory concentration testing. From the selected ESC-resistant E. coli isolates, $b l a_{\text {TEM }}$ was detected in $84.1 \%$, bla $a_{\mathrm{CMY}-2}$ was detected in $52.2 \%$, $b l a_{\mathrm{CTXM}}$ groups were detected in $30.7 \%$, and $b l a_{\mathrm{SHV}}$ was detected in $1.1 \%$ of isolates. Plasmid-mediated quinolone resistance genes were identified in 7 of 9 isolates resistant to quinolones. Five isolates were positive for
\end{abstract}

Received June 16, 2017.

Accepted December 18, 2017.

${ }^{1}$ Corresponding author: bawosile@upei.ca qnr $B$, whereas 2 isolates were positive for both $q n r B$ and $q n r S$. Whereas neonatal calves [odds ratio $(\mathrm{OR})=$ $2.42,95 \%$ confidence interval (CI): 1.87-3.12], regular ceftiofur use on the farm (OR $=3.83,95 \%$ CI: 2.29 $6.39)$, feeding of unpasteurized nonsalable milk (OR = 1.6, 95\% CI: 1.18-2.18), and use of florfenicol (OR = 2.02, 95\% CI: $1.43-2.86)$ were statistically associated with fecal recovery of $E$. coli with reduced susceptibility to ESC, use of ceftiofur for the treatment of respiratory diseases $(\mathrm{OR}=0.57,95 \%$ CI: $0.41-0.79)$ was statistically associated with decreased recovery of $E$. coli with reduced susceptibility to ESC. This study has provided information on the resistance genes associated with the occurrence of ESC and fluoroquinolone resistance in dairy calves within this region.

Key words: extended-spectrum cephalosporin, fecal shedding, Enterobacteriaceae, dairy calf

\section{INTRODUCTION}

Antimicrobial resistance (AMR) is a global concern in food animal production systems where AMR pathogens can contribute to increased morbidity and mortality of animals as well as public health concerns (van den Bogaard and Stobberingh, 2000; Call et al., 2008). In dairy calves, mortality and treatment costs are important causes of economic loss to the dairy industry (Donaldson et al., 2006). Various studies have shown that respiratory diseases and diarrhea are the most prevalent causes of death in calves from birth to weaning with Escherichia coli and Salmonella enterica being 2 of the major bacterial causes of diarrhea-associated mortality (Constable, 2004; Donaldson et al., 2006; Megersa et al., 2009).

Generic E. coli are abundant commensal enteric bacteria in animals and humans and are ubiquitous in the environment. They are commonly used as indicator bacteria for monitoring AMR dynamics, especially to very important antimicrobials such as ESC and fluoro- 
quinolones (DeFrancesco et al., 2004; Wang et al., 2006). Antimicrobial susceptibility patterns of $E$. coli reflect the selective pressure exerted by antimicrobial use and the potential of these bacteria to serve as a reservoir of AMR genes (European Food Safety Authority, 2012). These AMR genes, commonly found on plasmids, can be shared between bacteria, including Salmonella spp., in both humans and animals (Fluckey et al., 2007). Salmonella enterica is an important foodborne pathogen accounting for millions of cases of human infections worldwide (Public Health Agency of Canada, 2014). Salmonellosis is of clinical and production importance in both dairy and beef cattle operations causing illness and economic losses (Edrington et al., 2004). Salmonella Typhimurium, Salmonella Enteritidis, Salmonella Kentucky, Salmonella Montevideo, Salmonella Dublin, Salmonella Heidelberg, and Salmonella Newport are some of the major serovars associated with clinical infections in both human and cattle (Alexander et al., 2009; Jackson et al., 2013).

In Canada, extended-spectrum cephalosporins (ESC) are commonly used in both human and veterinary medicine. Although ceftiofur is recommended for undifferentiated bacterial pneumonia and acute bovine interdigital necrobacillosis, extra-label use for the treatment of gastroenteritis in dairy calves is also common (Canadian Veterinary Medical Association, 2008). According to the World Health Organization and Health Canada, ESC are considered to be critically important with respect to human medicine and are frequently prescribed for the treatment of invasive and life-threatening enteric infections including those caused by Escherichia coli and Salmonella enterica in humans (WHO, 2007; Veterinary Drugs Directorate, Health Canada, 2009). In dairy cattle, increased ESC resistance (ESC-R) has been widely reported in E. coli and $S$. enterica and is caused mainly by extended-spectrum $\beta$-lactamases (ESBL) or AmpC-type $\beta$-lactamases. Additionally, these organisms are commonly multi-drug resistant (MDR; Sawant et al., 2007; Daniels et al., 2009; Seiffert et al., 2013). The emergence of these MDR strains poses an increasing threat to the successful disease management in dairy calves (de Verdier et al., 2012). Dairy calves commonly harbor MDR bacteria with fecal shedding being most prevalent in the first few weeks of life (Berge et al., 2006a). Different studies have linked the fecal shedding of MDR E. coli and S. enterica to several factors including antimicrobial use (Berge et al., 2005; Daniels et al., 2009), age of calf (Hoyle et al., 2004; Berge et al., 2006a), type of housing (Pereira et al., 2014a), diets and feeding practices (Edrington et al., 2012), nonsalable milk feeding to dairy calves (Brunton et al., 2014; Randall et al., 2014; Duse et al., 2015) as well as long-term maintenance and occurrence of MDR E. coli in the absence of antimicrobial selection (Khachatryan et al., 2004).

Studies have examined and reported on the ESC resistance dynamics in dairy cattle within North America (Winokur et al., 2001; Heider et al., 2009a,b; Mollenkopf et al., 2012; Cormier et al., 2015). The ESC resistance has been predominantly attributed to the cephamycinase gene $b l a_{\mathrm{CMY}-2}$ and to a lesser extent to the ESBL resistance genes such as $b l a_{\mathrm{CTX}-\mathrm{M}}, b l a_{\mathrm{SHV}}$, and $b l a_{\text {TEM }}$ (Allen and Poppe, 2002; Mollenkopf et al., 2012; Schmidt et al., 2013).

Extended-spectrum $\beta$-lactamase producing Enterobacteriaceae, especially those with $b l a_{\mathrm{CTXM}-15}, b l a_{\mathrm{SHV}-5}$, and $b l a_{\mathrm{SHV}-7}$, have been associated with plasmid-mediated quinolone resistance (PMQR) genes (Nordmann, 2005). In most cases, both groups of genes (ESC and PMQR) are co-located on the same plasmid (Robicsek et al., 2006). However, limited reports are available of detection of PMQR genes in isolates from dairy cattle. Plasmid-mediated quinolone resistance genes mediated by $q n r S 1$ have been reported from an $E$. coli isolate from cattle in the United Kingdom (Kirchner et al., 2011). Other studies from the Netherlands and the United States have reported qnrB19 associated with E. coli from a veal calf (Hordijk et al., 2011) and 2 Salmonella isolates from environmental samples from a dairy farm (Cummings et al., 2017). Except for a study on E. coli mastitis on dairy farms (Saini et al., 2013), information on the fecal prevalence, risk factors associated with shedding, and the genetic mechanisms of resistance to ESC and quinolones of Salmonella enterica and ESC-R E. coli in dairy cattle in Atlantic Canada is limited.

The primary objectives of this study were to determine the frequency of fecal carriage and antimicrobial susceptibility patterns in S. enterica and ESC-R E. coli from Holstein dairy calves on 8 dairy farms in New Brunswick, Canada, using selective culture methods. Also, to determine the $\beta$-lactamase resistance genes associated with $S$. enterica and ESC-R E. coli. In addition, we explored the MDR in S. enterica and ESC-R E. coli, and when these MDR isolates had quinolone resistance, we examined if they harbored PMQR genes. Lastly, we determined the risk factors for fecal recoveries of Salmonella enterica and Escherichia coli with reduced susceptibility to ESC from Holstein dairy calves from these 8 farms in New Brunswick, Canada.

\section{MATERIALS AND METHODS}

\section{Sample Collection}

A convenience sample of 8 dairy farms from New Brunswick was recruited. Farms were visited on a fortnightly basis by their regular herd veterinarians 
to collect rectal fecal swabs from Holstein dairy calves from July 2014 to February 2015. The sample collection included 488 dairy calves born within this period. These calves were followed from the neonatal period to weaning (removal of all milk in the calves' diet). Rectal fecal swabs were collected using ready to use swab sticks (BBL CultureSwab collection and transport system, Becton and Dickinson and Company, Franklin Lakes, NJ) from 488 calves at 2 time points: 2 to 15 $\mathrm{d}$ old (neonatal) and 42 to $56 \mathrm{~d}$ old (weaning). Rectal swabs samples were shipped on ice, via courier, to the laboratory following every collection. Samples were processed the same day they were received in the laboratory.

\section{Isolation and Identification of Salmonella enterica}

Fecal swabs were pre-enriched in $10 \mathrm{~mL}$ of buffered peptone water (BPW) and then incubated at $35^{\circ} \mathrm{C}$ for 18 to $24 \mathrm{~h}$. Aliquots $(200 \mu \mathrm{L})$ of incubated preenrichment broth were struck on modified semi-solid Rappaport-Vassiliadis agar plates (Becton Dickinson and Co., Franklin Lakes, NJ). The plates were incubated at $42^{\circ} \mathrm{C}$ and then examined for migration pattern typical of $S$. enterica ( $\geq 20 \mathrm{~mm}$ migration) every 24 $\mathrm{h}$ for a total of $72 \mathrm{~h}$. Presumptive Salmonella isolates were sub-cultured onto MacConkey agar, and 3 to 5 nonlactose-fermenting colonies were purified by subculturing onto tryptic soy agar supplemented with $5 \%$ sheep blood. Salmonella enterica were further identified by triple sugar iron test, utilization of citrate, urease production, and Salmonella O antiserum Poly A-I \& Vi. All isolates were frozen in Brucella broth with $15 \%$ glycerol at $-80^{\circ} \mathrm{C}$. Salmonella serotyping was carried out by the OIE Salmonella Reference Laboratory, National Microbiology Laboratory, Public Health Agency of Canada, Guelph, Ontario.

\section{Isolation and Identification of Suspected Extended- Spectrum Cephalosporin-Resistant E. coli}

The initial enrichment process for the isolation of $E$. coli was carried out following methods used by the Canadian Integrated Program for Antimicrobial Resistance Surveillance (Government of Canada, 2010). In brief, an initial pre-enrichment was carried out by incubating the fecal swab in $10 \mathrm{~mL}$ of BPW overnight at $35^{\circ} \mathrm{C}$ for 18 to $24 \mathrm{~h}$. Selective enrichment was carried out by adding an equal volume $(10 \mathrm{~mL})$ of the incubated BPW to double-strength Escherichia coli broth and incubated at $45^{\circ} \mathrm{C}$ for 18 to $24 \mathrm{~h}$. A tryptic soy agar plate with $5 \%$ sheep blood containing vancomycin $(6 \mu \mathrm{g} / \mathrm{mL})$, ceftazidime $(2 \mu \mathrm{g} / \mathrm{mL})$, amphotericin
B $(2 \mu \mathrm{g} / \mathrm{mL})$, and clindamycin $(1 \mu \mathrm{g} / \mathrm{mL} ;$ VACC $)$ was used for selective culture of $E$. coli with reduced susceptibility to ESC [suspected extended-spectrum cephalosporin-resistant (sESC-R) E. coli; Singh et al., 2012]. The VACC agar was inoculated with $50 \mu \mathrm{L}$ of inoculated E. coli broth and incubated at $37^{\circ} \mathrm{C}$ for 18 to $24 \mathrm{~h}$. If no presumptive colonies grew, then the VACC agar plates were incubated for an additional 18 to $24 \mathrm{~h}$. Suspected ESC-R E. coli isolates (3-5 isolates per plate depending on colony morphology) were sub-cultured to eosin methylene blue agar, and typical colony types were purified on tryptic soy agar supplemented with $5 \%$ sheep blood. Escherichia coli were identified by lactose-fermentation, inability to use citrate, and lack of urease production. All the isolates were frozen in Brucella broth with $15 \%$ glycerol at $-80^{\circ} \mathrm{C}$ for further laboratory analysis.

\section{Antimicrobial Susceptibility Testing}

From all the sESC-R E. coli isolates that grew on the VACC agar, a subset of 100 isolates was randomly selected with at least 8 isolates per farm being selected for antimicrobial susceptibility testing. All of the recovered Salmonella isolates were included for antimicrobial susceptibility testing. Broth microdilution using the Sensititer system was used to determine MIC of the isolates. This method conformed to the Clinical and Laboratory Standards Institute standards (CLSI, 2015) and protocols developed by the Canadian Integrated Program for Antimicrobial Resistance Surveillance (Government of Canada, 2010). The CMV2AGNF (Sensititer, Trek Diagnostic Systems, Westlake, OH) gram-negative panel for the National Antimicrobial Monitoring System containing 15 antimicrobials was used in this study. The following antimicrobial agents were tested with the resistance breakpoints presented in parentheses: ampicillin $(\geq 32 \mu \mathrm{g} / \mathrm{mL})$, amoxicillin-clavulanic acid $(\geq 32 / 16$ $\mu \mathrm{g} / \mathrm{mL}$, chloramphenicol $(\geq 32 \mu \mathrm{g} / \mathrm{mL})$, ceftriaxone $(\geq 4 \mu \mathrm{g} / \mathrm{mL})$, ceftiofur $(\geq 8 \mu \mathrm{g} / \mathrm{mL})$, ciprofloxacin $(\geq 1$ $\mu \mathrm{g} / \mathrm{mL})$ cefoxitin $(\geq 32 \mu \mathrm{g} / \mathrm{mL})$, gentamicin $(\geq 16 \mu \mathrm{g} /$ $\mathrm{mL})$, kanamycin $(\geq 64 \mu \mathrm{g} / \mathrm{mL})$, nalidixic acid $(\geq 32 \mu \mathrm{g} /$ $\mathrm{mL})$, streptomycin $(\geq 64 \mu \mathrm{g} / \mathrm{mL})$, sulfisoxazole $(\geq 512$ $\mu \mathrm{g} / \mathrm{mL})$, trimethoprim-sulfamethoxazole $(\geq 4 / 76 \mu \mathrm{g} /$ $\mathrm{mL})$, and tetracycline $(\geq 16 \mu \mathrm{g} / \mathrm{mL})$. The resistance breakpoints used for these antimicrobials were based on CLSI guidelines (CLSI, 2015). Azithromycin was on the panel but was excluded from analysis because of the intrinsic resistance of $E$. coli to the antimicrobial.

The ESC-R E. coli was defined as a sESC-R E. coli that showed MIC resistance to either ceftriaxone or ceftiofur, or both, based on their MIC breakpoints. Multi-drug resistance was defined as resistance to at 
least one antimicrobial in at least 3 or more antimicrobial categories, as described by the World Health Organization (Magiorakos et al., 2012).

\section{$\beta$-Lactamase and Plasmid-Mediated Quinolone Resistance Gene Detection}

$\beta$-Lactamase gene detection was carried out on all the isolates selected for antimicrobial susceptibility testing. Genomic DNA was extracted using a commercial kit (InstaGene Matrix Bio-Rad, Montreal, Canada). Two multiplex PCR were performed for the molecular detection of $\beta$-lactamase genes. The first multiplex PCR for the detection of $b l a_{\mathrm{CMY}-2}, b l a_{\mathrm{SHV}}$, and $b l a_{\mathrm{TEM}}$ was carried out using the consensus primers and amplification protocol that was previously described (Kozak et al., 2009). The second multiplex PCR was carried out to determine the different $b l a_{\text {СтХ-м }}$ groups (group 1, 2, and 9) using consensus primers and the amplification protocol previously described (Dallenne et al., 2010). All cultured isolates exhibiting quinolone resistance by MIC were further characterized for the PMQR genes: $q n r B$ group and qnr $S$ group genes. This characterization was done using the multiplex PCR protocol and primers described by Cattoir et al. (2007).

For all multiplex PCR, a Qiagen Multiplex PCR Master Mix Kit (Qiagen, Mississauga, Ontario, Canada) with $1 \times$ Qiagen multiplex PCR master mixture, $1 \times$ Q-solution, and molecular grade water, $1 \times$ consensus primer pair mixture, as well as $2 \mu \mathrm{L}$ of the isolate's DNA template were included in the final $25-\mu \mathrm{L}$ mixture according to the manufacturer's instructions. Amplification was carried out in a PCR thermocycler (Techne TC-412, Thermo Fisher Scientific, Mississauga, Ontario, Canada). Both positive and negative controls were included in every multiplex PCR. Fragments of DNA were analyzed by electrophoresis on a $1.0 \%$ agarose gel at $100 \mathrm{~V}$ for $1 \mathrm{~h}$ in $1 \times$ Tris-boric acid-EDTA containing $1 \mu \mathrm{g} / \mathrm{mL}$ of ethidium bromide.

\section{Risk Factor Analysis: Descriptive, Unconditional, and Multivariable Models}

Data management was done using Microsoft Excel for Windows (2010, Microsoft Corp., Redmond, WA) and then imported to STATA/IC 14.0 (StataCorp, College Station, TX) for analysis. Risk factors for the fecal recovery of $S$. enterica and sESC-R $E$. coli were determined using the information from a questionnaire. Information collected through the questionnaire was number of cows and preweaned calves within the herd; breed of cattle; cow and calf housing types; feeding practices of unpasteurized nonsalable milk to calves; ceftiofur use, frequency of use and what disease conditions ceftiofur was used for; previous history of salmonellosis on the farm; and information on other antimicrobials used on the farm. The questionnaires were mailed to the herd veterinarians who provided them to the enrolled farms; the producers completed the questionnaire and returned to the herd veterinarians who forwarded them to the researchers. For risk factor analysis, all the predictors assessed except calf age at sampling were at the farm level. Initial descriptive statistics were done to summarize the various predictors of interest as well as the outcomes of interest. Collinearity between the variables was assessed using the variance-covariance matrix estimates and Spearman correlations. For highly correlated variables, one of the variables was selected to be included in the subsequent modeling process.

The data structure in this study was a 3-level hierarchical structure with the farm at the highest level, calf as the second level, and the repeated sampling time was the lowest level. Univariable logistic regression models were carried out to determine the candidate variables for multivariable models. Predictors that were significant at $P$-values $\leq 0.20$ in the univariate analysis were included in the subsequent multivariable regression model. We first used this data structure to set up a 3-level mixed effects model to examine if the predictors accounted for the farm level variance. However, in the mixed effect model, after accounting for the predictors, the variability between farms disappeared, with all the variation occurring at the calf level. Therefore, calf level hierarchy was used in the subsequent multivariable model. Given that there were only 2 observations per calf, a generalized estimating equation model was initially compared with multivariable logistic regression. Due to the similarity in these models, a population average multivariable logistic regression model (adjusting for clustering at calf level) was subsequently fitted for each outcome of interest. Then the model assessment was carried out by checking the residuals, identifying influential observations, and evaluating the reliability of the model (Dohoo et al., 2010). Confounding and interaction between the variables were examined based on the use of a causal diagram. The goodness of fit test of the model was assessed using either Pearson or Hosmer-Lemeshow tests. The Wald test was used to test for the significance of predictors. Predictors with $P$-values $\leq 0.05$ were retained in the final model. Odds ratios were computed and interpreted as a population average. Odds ratio $<1$ between a variable and the outcome was considered protective, whereas odds ratio $>1$ was considered a risk factor. 


\section{RESULTS}

\section{Frequency of Fecal Carriage and MIC Profile of Salmonella enterica Isolated from Dairy Calves}

Sixteen (16) of the 488 calves $(3.3 \%)$ were shedding Salmonella enterica on at least 1 of the 2 sample times. All $S$. enterica isolates were from 4 of the 8 farms $(50 \%)$, and the within-herd frequency on the 4 positive farms ranged from 2.1 to $6.3 \%$. The Salmonella isolates belonged to 3 serovars, namely Salmonella Senftenberg, Salmonella Typhimurium DT02, and Salmonella Derby. All Salmonella serovars clustered on farms with Salmonella Senftenberg isolated from 2 farms, whereas Salmonella Typhimurium and Salmonella Derby were found on one farm each. Shedding was more likely to occur during at the neonatal period $(3.3 \%)$ compared with the weaning period $(0.82 \% ; P=0.0067)$. All 4 calves that were positive at weaning were also positive during the neonatal period. Salmonella enterica isolates were pansusceptible to all antimicrobials on the MIC panel except one isolate that was resistant to sulfisoxazole.

\section{Frequency of Fecal Carriage of sESC-R E. coli from Dairy Calves and MIC Profiles of Selected sESC-R E. coli}

Escherichia coli with sESC-R, based on selective culture media, were isolated from 396 of 488 calves $(81.2 \%)$ over the study period. Fifty-two percent (205 calves) of calves positive for sESC-R E. coli were positive at both the neonatal and weaning periods. The within-herd frequency of shedding of sESC-R E.coli ranged from 75 to $98.4 \%$. Significant differences $(P$ $<0.0001$ ) were observed in the frequency of recovery of sESC-R E. coli between the neonatal (71.1\%) and weaning (51.1\%) periods. From the 100 selected sESCR E. coli isolates for MIC testing (Table 1), resistance was commonly observed to ampicillin (100\%), tetracycline $(94 \%)$, sulfisoxazole (94\%), amoxicillin/clavulanic acid (89\%), streptomycin (100\%), ceftriaxone (88\%), cefoxitin (84\%), and ceftiofur (85\%). Nine percent of sESC-R E. coli isolates were nalidixic acid resistant and also showed intermediate susceptibility to ciprofloxacin. Based on MIC testing, $88 \%$ of the selected sESC-R $E$. coli were confirmed ESC-R and were all MDR (Table $2)$.

\section{Frequency of $\beta$-Lactamase Resistance Genes in the Selected sESC-R E. coli}

All 100 sESC-R E.coli isolates were examined for the presence of ESC resistance genes. In the $88 \mathrm{E}$. coli isolates confirmed to be ESC-R based on MIC testing,

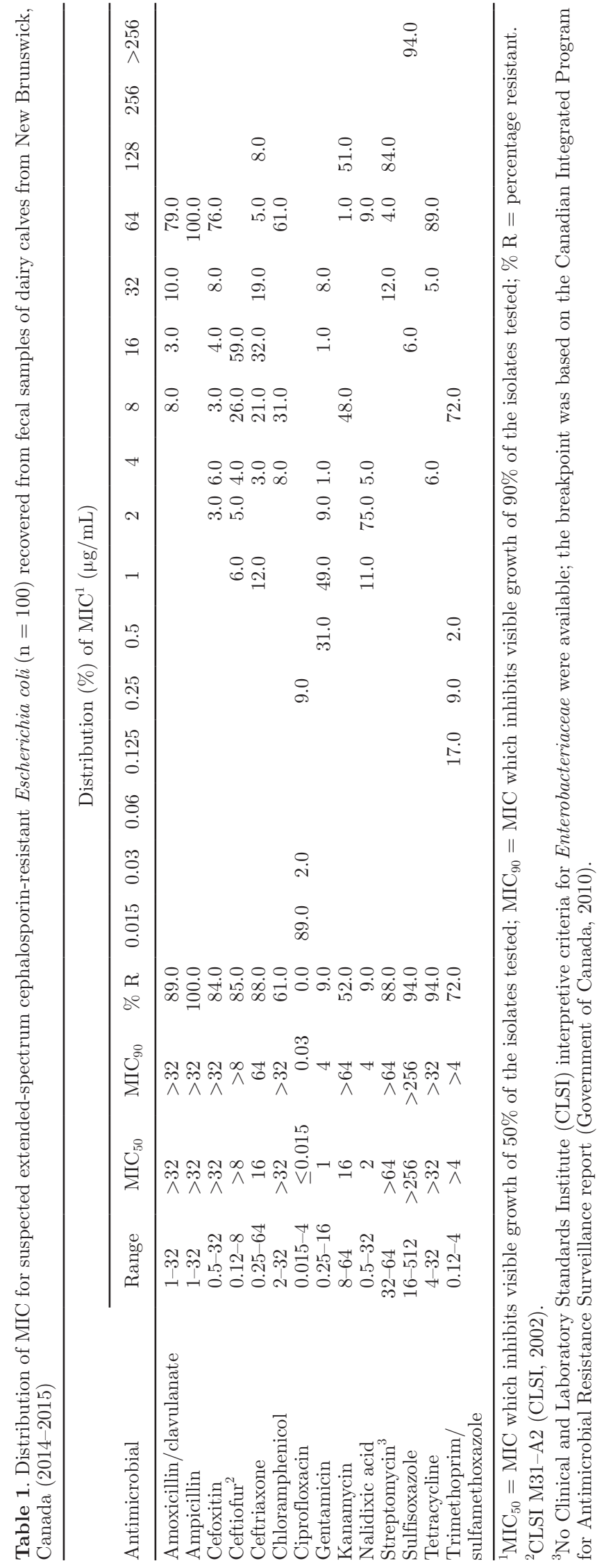

Journal of Dairy Science Vol. 101 No. 4, 2018 
Table 2. Multi-drug resistance patterns of selected 88 extended-spectrum cephalosporin-resistant Escherichia coli isolated from Holstein dairy calves $(2014-2015)^{1}$

\begin{tabular}{llrc}
\hline No. & Multi-drug resistance pattern & Frequency & $\%$ \\
\hline 1 & A-Ag-C-Cax-Cef-Fox-Kan-Str-Sul-Tms-Tet & 22 & 25.00 \\
2 & A-Ag-C-Cax-Cef-Fox-Str-Sul-Tms-Tet & 13 & 14.77 \\
3 & A-Ag-Cax-Cef-Fox-Str-Sul-Tms-Tet & 13 & 14.77 \\
4 & A-Ag-Cax-Cef-Fox-Nal-Str-Sul-Tms-Tet & 7 & 7.95 \\
5 & A-C-Cax-Cef-Kan-Str-Sul-Tms-Tet & 6 & 6.82 \\
6 & A-Ag-C-Cax-Cef-Fox-Gm-Str-Sul-Tms-Tet & 4 & 4.55 \\
7 & A-Ag-C-Cax-Cef-Fox-Kan-Str-Sul-Tet & 4 & 4.55 \\
8 & A-Ag-C-Cax-Cef-Fox-Str-Sul-Tet & 3 & 3.41 \\
9 & A-Ag-C-Cax-Kan-Str-Sul-Tet & 2 & 2.27 \\
10 & A-Ag-Cax-Cef-Fox-Str & 2 & 2.27 \\
11 & A-Ag-C-Cax-Cef-Fox-Kan-Nal-Str-Sul-Tms-Tet & 1 & 1.14 \\
12 & A-Ag-C-Cax-Cef-Gm-Kan-Str-Sul-Tet & 1 & 1.14 \\
13 & A-Ag-C-Cax-Cef-Kan-Str-Sul-Tet & 1 & 1.14 \\
14 & A-Ag-C-Cax-Cef-Kan-Str-Sul-Tms-Tet & 1 & 1.14 \\
15 & A-Ag-Cax-Cef-Fox-Gm-Str-Sul-Tet & 1 & 1.14 \\
16 & A-Ag-Cax-Cef-Fox-Kan-Nal-Str-Sul-Tms-Tet & 1 & 1.14 \\
17 & A-Ag-Cax-Cef-Fox-Str-Tet & 1 & 1.14 \\
18 & A-Ag-Cax-Cef-Gm-Str-Sul-Tms-Tet & 1 & 1.14 \\
19 & A-C-Cax-Cef-Gm-Str-Sul-Tms-Tet & 1 & 1.14 \\
20 & A-Cax-Cef-Gm-Kan-Str-Sul & 1 & 1.14 \\
21 & A-Cax-Cef-Gm-Str & 1 & 1.14 \\
22 & A-Cax-Cef-Str & 1 & 1.14 \\
\hline${ }^{1}$ A = ampicillin; Ag = amoxicillin-clavulanate; C = chloramphenicol; Cax = ceftriaxone; Cef = ceftiofur; Fox $=$ \\
cefoxitin; Gm = gentamicin; Kan = kanamycin; Nal= nalidixic acid; Str = streptomycin; Sul = sulfisoxazole; \\
Tms = trimethoprim-sulfamethoxazole; Tet = tetracycline. & &
\end{tabular}

$b l a_{\mathrm{TEM}}$ was detected in $84.1 \%, b l a_{\mathrm{CMY}-2}$ was detected

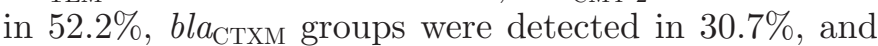
$b l a_{\mathrm{SHV}}$ was detected in $1.1 \%$ of isolates. Of the $b l a_{\mathrm{CTXM}^{-}}$ producing isolates, the frequency of detection of the phylogenetic groups was $9.1 \% b l a_{\mathrm{CTXM}-1}, 9.1 \% b l a_{\mathrm{CTXM-2}}$, and $15.9 \% b l a_{\text {Стхм-9 }}$ for all ESC-R E. coli. Forty-eight percent $(48 \%)$ of ESC-R $E$. coli had $2 \beta$-lactamase resistance genes, and $12.5 \%$ had 3 resistance genes (Table 3). Only one isolate was negative for all ESC-R genes that were tested. Six farms were $b l a_{\text {СтXм }}$ positive; of the phylogenetic groups 2 farms were $b l a_{\text {CTXM-1 }}$ positive, 4 farms were $b l a_{\text {Стхм-9 }}$ positive, and 3 farms were $b l a_{\mathrm{CTXM}-2}$ positive. Both $b l a_{\mathrm{CMY}-2}$ and $b l a_{\mathrm{TEM}}$ resistance genes were detected on all 8 farms. In the 12 sESC-R,

Table 3. $\beta$-Lactamase resistance genes patterns in extended-spectrum cephalosporin-resistant Escherichia coli isolated from Holstein dairy calves $(\mathrm{n}=88)$ from 8 herds in New Brunswick, Canada (2014-2015)

\begin{tabular}{|c|c|c|}
\hline$\beta$-Lactamase pattern & Frequency & $\%$ \\
\hline 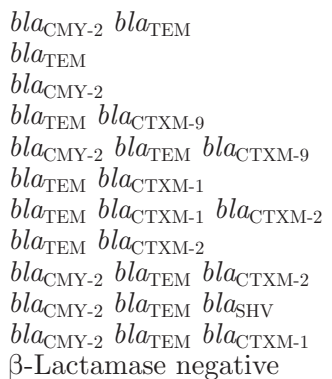 & $\begin{array}{r}25 \\
21 \\
13 \\
10 \\
4 \\
4 \\
3 \\
3 \\
2 \\
1 \\
1 \\
1\end{array}$ & $\begin{array}{r}28.41 \\
23.86 \\
14.77 \\
11.36 \\
4.55 \\
4.55 \\
3.41 \\
3.41 \\
2.27 \\
1.14 \\
1.14 \\
1.14\end{array}$ \\
\hline
\end{tabular}

E. coli isolates that were ESC susceptible on MIC testing, 11 (11) isolates were $b l a_{\text {TEM }}$ positive, and 4 of these 11 isolates were also $b l a_{\mathrm{CMY}-2}$ positive.

\section{$P M Q R$ Genes in ESC-R E. coli with Quinolone Resistance Based on MIC Testing}

Based on the MIC testing, 9 isolates were nalidixic acid resistant and also had an intermediate susceptibility to ciprofloxacin. Plasmid-mediated quinolone resistance genes were detected from 7 of the 9 isolates. Only 5 isolates were positive for $q n r B$ alone; 2 isolates were positive for both $q n r B$ and $q n r S$, whereas 2 other isolates were negative for any PMQR genes.

\section{Risk Factors for the Fecal Recovery of Salmonella enterica and $s E S C-R E$. coli}

Descriptive Analysis. The herd demographic information and characteristics of the 8 farms in this study are presented in Tables 4 and 5 . The number of cows in all the 8 herds ranged from 76 to 700 lactating cows with an average of 236 cows per herd, whereas the number of neonatal calves ranged from 6 to 45 with an average of 23 per herd. Most of the herds were freestall farms (6/8), and 5 herds housed neonatal calves in hutches. Five of the 8 herds housed sick cattle separately from others. In 5 herds, calves were fed unpasteurized waste milk. None of the herds had any previ- 
Table 4. Herd and calf level continuous variable descriptions of the 8 dairy farms from New Brunswick, Canada (2014-2015)

\begin{tabular}{lc}
\hline Variable & Average (range) \\
\hline No. of cows/herd & $236(76-700)$ \\
No. of preweaned calves/herd & $23(6-45)$ \\
Milk rolling $(\mathrm{kg})$ & $8,884.4(1,900-12,000)$ \\
Milk/cow per d $(\mathrm{kg})$ & $34.2(29.5-38)$ \\
SCC $(\mathrm{cfu} / \mathrm{mL})$ & $162,500(70,000-300,000)$ \\
\hline
\end{tabular}

ous history of salmonellosis on the farms. Ceftiofur was used in all herds and was used for the management of diseases such as lameness (2 herds), respiratory diseases (4 herds), reproductive diseases ( 4 herds), and foot rot ( 3 herds). Ceftiofur was regularly used in 6 of the herds (Ceftiofur use equal to daily, weekly, or monthly use was considered regular use, whereas occasional use was considered as use at a point in time that was greater than $1 \mathrm{mo}$ ). Other antimicrobials reportedly used for the treatments of diseases on the farms were florfenicol (4 herds), penicillin (2 herds), tulathromycin (1 herd), and trimethoprim-sulfadoxine (1 herd).

Risk Factors for the Fecal Recovery of Salmonella enterica. Calf age, feeding of unpasteurized waste milk, separation of sick cows from other cattle, and use of ceftiofur for the treatment of respiratory diseases were significantly associated with the fecal re- covery of Salmonella enterica $(P \leq 0.05)$ in the univariable regression model. However, other factors including use of penicillin, use of florfenicol, use of ceftiofur for the treatment of scours, and use of ceftiofur for the treatment of lameness were associated with the fecal recovery of Salmonella enterica at $P \leq 0.20$ in the univariable analysis (Table 6). Due to the low number of isolates, a multivariable model could not be fitted for this outcome.

Risk Factors for the Fecal Recovery of sESC-R E. coli. For sESC-R E. coli in calves' feces, average number of cows per herd, average number of calves per herd, lactating cow housing, calf age at sampling, feeding of unpasteurized nonsalable milk, frequency of ceftiofur use, disease conditions for the use of ceftiofur on the farms (lameness, scours, respiratory diseases, foot rot, metritis and mastitis), and the use of other antimicrobials (florfenicol, penicillin, tulathromycin, and trimethoprim-sulfadoxine) were unconditionally associated $(P \leq 0.25)$ with fecal recovery of sESC-R $E$. coli at the univariable level (Table 7).

A high correlation was observed between the feeding of unpasteurized nonsalable milk, lactating cow housing, and disease conditions for the use of ceftiofur on the farms. Therefore, feeding of unpasteurized nonsalable milk was used in the subsequent model

Table 5. Herd and calf level categorical variable descriptions of the 8 dairy farms from New Brunswick, Canada (2014-2015)

\begin{tabular}{|c|c|c|}
\hline Variable & Category & Frequency $(\%)$ \\
\hline \multirow{2}{*}{ Preweaned calves' housing } & Calf hutch & $5(62.5)$ \\
\hline & Group & $3(37.5)$ \\
\hline Lactating cow housing & Tiestall & $2(25.0)$ \\
\hline \multirow[t]{2}{*}{ Sick cows housed separately from other cows } & Yes & $5(62.5)$ \\
\hline & No & $3(37.5)$ \\
\hline \multirow[t]{2}{*}{ Previous history of salmonellosis on farms } & Yes & $0(0.0)$ \\
\hline & No & $8(100.0)$ \\
\hline \multirow[t]{2}{*}{ Ceftiofur use on the farms } & Yes & $8(100)$ \\
\hline & No & $0(0.0)$ \\
\hline \multirow{2}{*}{ Frequency of ceftiofur use on the farms } & Regularly & $6(75.0)$ \\
\hline & Occasionally & $2(25.0)$ \\
\hline Previous history of ceftiofur use on the farm for treatment of salmonellosis & Yes & $0(0.0)$ \\
\hline \multirow{5}{*}{ Disease conditions in which ceftiofur was used on the farms } & Scours & $2(25.0)$ \\
\hline & Metritis/retained placenta & $5(62.5)$ \\
\hline & Anorexia/general infection & $2(25.0)$ \\
\hline & Footrot & $3(37.5)$ \\
\hline & Mastitis & $1(12.5)$ \\
\hline \multirow[t]{4}{*}{ Other antimicrobials used for the treatments of diseases on the farm within the last 6 mo } & Florfenicol & $4(50.0)$ \\
\hline & Penicillin & $2(25.0)$ \\
\hline & Trimethoprim-sulfadoxine & $1(12.5)$ \\
\hline & Tulathromycin & $1(12.5)$ \\
\hline
\end{tabular}


building process because previous reports documented the relationship between the feeding of unpasteurized nonsalable milk and fecal shedding MDR bacteria in dairy calves. Additionally, collinearity was also observed between penicillin, florfenicol, tulathromycin, and trimethoprim-sulfadoxine. Florfenicol was selected for subsequent analysis. Four covariates from 4 farms were influential in the model building. Three of these were from the farms that used ceftiofur regularly as well as fed unpasteurized nonsalable milk. The fourth observation was from a farm that also used ceftiofur regularly but did not feed unpasteurized nonsalable milk to calves. One of these covariates produced a lack of fit and had a strong effect on the coefficient of use of ceftiofur for the treatment of respiratory diseases. This influential covariate was from a herd that fed waste milk to calves and used ceftiofur regularly. However, it was negative for sESC-R E. coli and was from fecal samples of calves during the weaning period. Based on predictability and reliability of the model, the model was highly sensitive (86.52\%), but less specific (40\%).

Five variables remained in the multivariable model and were significantly associated with recovery of sESC-R E. coli from calf feces (Table 8). None of the interaction terms among the variables were significant. Recovery of sESC-R E. coli was more likely in neonates than those of weaning age [odds ratio $(\mathbf{O R})=2.42$, 95\% CI: 1.87-3.12], farms reporting regular ceftiofur use versus occasional use (OR $=3.83,95 \%$ CI: 2.29 6.39), farms feeding unpasteurized nonsalable milk to calves $(\mathrm{OR}=1.61,95 \% \mathrm{CI}: 1.18-2.18)$, and the use of florfenicol (OR $=2.02,95 \%$ CI: 1.43-2.86). Recovery of sESC-R E. coli was less likely when ceftiofur was used versus nonuse for the treatment of respiratory diseases $(\mathrm{OR}=0.57,95 \%$ CI: 0.41-0.79).

\section{DISCUSSION}

The frequency of fecal recovery of Salmonella enterica in this study was low, although similar to the low prevalence reported in Alberta, Canada (Sorensen et al., 2003), but lower than that reported by Abouzeed et al. (2000) in Prince Edward Island beef cattle. This low frequency in addition to the pansusceptibility of recovered isolates to tested antimicrobials may suggest that Salmonella enterica is of low risk to dairy cattle within this region. Host-specific Salmonella serovars Dublin and other common serovars commonly isolated from

Table 6. Univariable logistic regression of variables unconditionally associated with fecal recovery of Salmonella enterica $(2014-2015)^{1}$

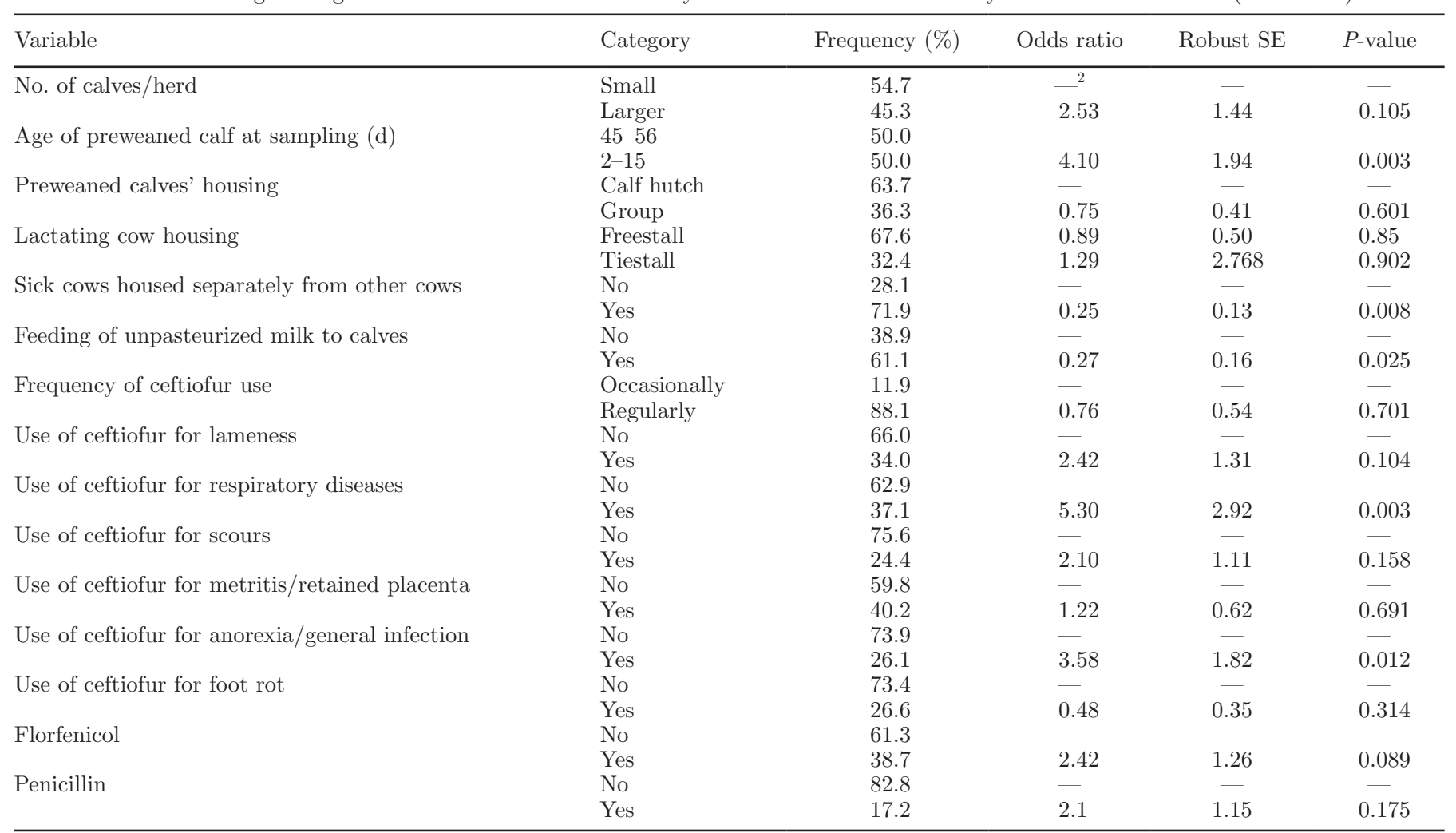

${ }^{1}$ Observations for number of cows/herd, trimethoprim-sulfadoxine, tulathromycin, and mastitis were too low to allow for analysis. Number of calves/herd: small: $<23$ calves/herds, larger: $\geq 23$ calves/herd.

2_: reference. 
Table 7. Univariable logistic regression of variables unconditionally associated with fecal recovery of suspected extended-spectrum cephalosporinresistant Escherichia coli $(2014-2015)^{1}$

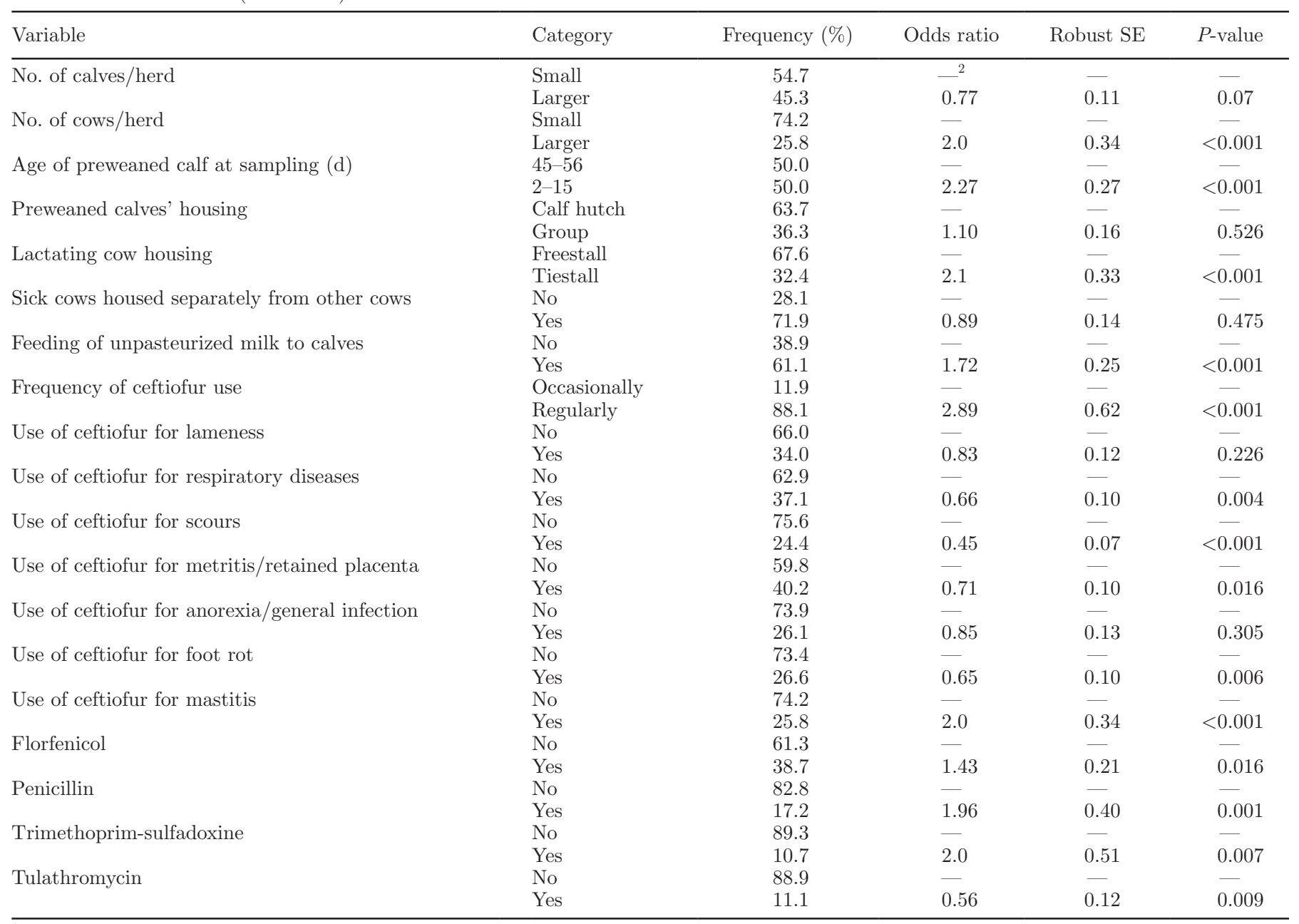

${ }^{1}$ Number of calves/herd: small, $<23$ calves/herds; larger, $\geq 23$ calves/herd.

2-: reference.

both healthy and diarrheic cattle such as Newport, Typhimurium DT 104, and Montevideo in North America (Abouzeed et al., 2000; Wells et al., 2001; Berge et al., 2006a) were not isolated in this study. All of the isolates serotyped belonged to 3 serovars: Senftenberg, Typhimurium DT02, and Derby. To our knowledge, this is the first reported isolation of Salmonella Typhimurium DT02 in dairy cattle in Canada. Although Salmonella

Table 8. Population average multivariable logistic regression of predictors associated with fecal recovery of suspected extended-spectrum cephalosporin-resistant Escherichia coli (2014-2015)

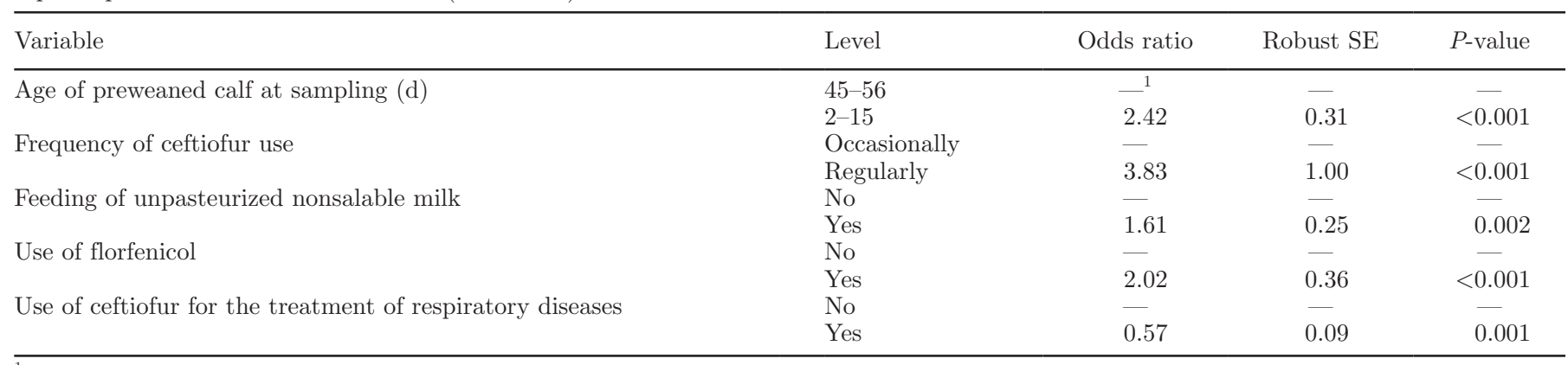

\footnotetext{
1_: reference.
} 
Senftenberg has been isolated from dairy cattle, this serovar is considered to be less important and one of the infrequent serotypes of nonclinical bovine isolates (Centers for Disease Control and Prevention, 2002). However, it was reported recently as one of the serovars of nontyphoidal salmonellosis in humans (Centers for Disease Control and Prevention, 2016).

Salmonella Derby isolated from dairy calves in this study is more host specific and adapted to pigs and is reported to cause clinical salmonella infections in humans (Philippczik et al., 1999). Salmonella Typhimurium DT02 has a narrow host range and more commonly causes infections in pigeons (Rabsch, 2002). The isolation of Salmonella Typhimurium DT02 in dairy calves may further support the importance of birds that frequent dairy farms in transmitting disease-causing pathogens as well as being reservoirs of foodborne pathogens (Kirk et al., 2002). The Salmonella enterica isolates recovered in this study were pansusceptible, which is consistent with other published reports both in Canada (Sorensen et al., 2003) and the United States (Berge et al., 2006a).

Different studies have reported on the prevalence of sESC-R E. coli in dairy calves using selective culture. Eighty-one percent $(81 \%)$ of calves were positive for SESC-R E. coli in this study, which was lower than the 93 and $88 \%$ reported by Donaldson (Donaldson et al., 2006) and Davis (Davis et al., 2015), respectively, in the United States. Fecal prevalences of 34.4 to $61 \%$ have been reported from Ohio dairy cattle (Tragesser et al., 2006; Heider et al., 2009a). Previous studies have reported that calves are colonized with MDR bacteria including Escherichia coli at an early age with subsequent shedding, especially within the first 2 wk of life (Berge et al., 2005; Donaldson et al., 2006; Edrington et al., 2012).

In this study, $88 \%$ of the selected sESC-R-E.coli isolates that grew on VACC agar demonstrated phenotypic resistance to ESC (ceftriaxone, ceftiofur, or both) on MIC testing. These ESC-R isolates also had co-resistance to at least 3 or more other antimicrobial categories, thus fitting the definition of MDR isolates. The most common co-resistance with ESC was with streptomycin, sulfisoxazole, trimethoprim-sulfamethoxazole, and tetracycline versus the commonly reported co-resistance to fluoroquinolones and aminoglycosides (Cantón et al., 2012; Seiffert et al., 2013).

Four different $\beta$-lactamase genes were detected in this study belonging to Ambler molecular classes A $\left(b l a_{\mathrm{TEM}}, b l a_{\mathrm{CTX}-\mathrm{M}}\right.$, and $\left.b l a_{\mathrm{SHV}}\right)$ and $\mathrm{C}\left(b l a_{\mathrm{CMY}-2}\right)$. These $\beta$-lactamase resistance genes have also been recently reported from beef cattle in Alberta, Canada, however, at varying proportions compared with this study (Cormier et al., 2015). Detection of $b l a_{\mathrm{TEM}}, b l a_{\mathrm{CMY}-2}, b l a_{\mathrm{CTX}-\mathrm{M}}$, and $b l a_{\mathrm{SHV}}$ explains most of the causes of the ESC-R in $E$. coli isolates in this study. Nondetection of these ESC resistance genes in one ESC-R E. coli isolate suggests the presence of other mechanisms of ESC resistance, such as efflux pumps or chromosomal-mediated resistance determinants. The 12 sESC-R E. coli isolates that did not have phenotypic evidence of ESC resistance based on MIC testing were resistant to ampicillin, amoxicillinclavulanate $(\beta$-lactam/ $\beta$-lactamase inhibitor combination), and cefoxitin. This $\beta$-lactam/ $\beta$-lactamase inhibitor resistance may indicate that the $b l a_{\text {TEM }}$ resistance genes detected in the ESC-susceptible isolates were not ESBL but may be inhibitor-resistant $b l a_{\text {TEM }}$. However, the presence of cefoxitin resistance in all the suspected inhibitor resistant $b l a_{\text {TEM }}$ isolates and detection of the $b l a_{\mathrm{CMY}-2}$ resistance gene in another 4 isolates may suggest the existence of 2 or more $\beta$-lactamase resistance mechanisms (Cantón et al., 2008).

The ESC-R in cattle within North America has been attributed mainly to the bla $a_{\mathrm{CMY}-2}$ resistance gene (Donaldson et al., 2006; Mollenkopf et al., 2012; Cormier et al., 2015). Even though $b l a_{\mathrm{CMY}-2}$ was detected from all the farms, $b l a_{\text {TEM }}$ was the more commonly observed $\beta$-lactamase resistance gene in this study.

Previous studies within Canada have characterized and reported the $b l a_{\mathrm{CMY}-2}$ gene and its associated plasmid dynamics in S. enterica and E. coli from human, cattle, environmental sources, and meat products (Forward et al., 2004; Mulvey et al., 2009; Mataseje et al., 2010; Martin et al., 2012). However, compared with bla $a_{\mathrm{CMY}-2}$, studies on bla $a_{\text {CTX-M }}$ resistance genes in Canadian cattle are limited. In Europe, the $b l a_{\mathrm{CTX}-\mathrm{M}}$ resistance gene is known and reported to be the most common cause of ESC resistance in the Enterobacteriaceae (Seiffert et al., 2013). No $b l a_{\text {СтХ-м }}$ resistance genes were reported from animals in Canada over a decade ago ( $\mathrm{Li}$ et al., 2007), although they were commonly reported in E. coli as a major cause of community-acquired infections in humans (Pitout et al., 2004b). In this study, 30.7\% of selected sESC-R E. coli isolates were carriers of $b l a_{\text {CTX-M }}$ resistance genes. To the best of our knowledge, this is the first report of detection of bla $a_{\text {CTX-M }}$ resistance genes in dairy calves within Atlantic Canada.

Two different groups of bla $a_{\mathrm{CTX}-\mathrm{M}}$ were detected in this study (groups 1 and 9). They are the most widely distributed $b l a_{\text {СтХ-м }}$ groups in both human and animal bacterial isolates, especially $b l a_{\text {CTX-M-15 }}$ of group 1 and $b l a_{\text {CTX-M-14 }}$ of group 9 in North America and other parts of the world (Pitout et al., 2004a; Cantón et al., 2012). The detection of $b l a_{\text {Стх-м }}$ in this study together with other recent reports from beef cattle from western Canada (Cormier et al., 2015) and dairy cattle from the United States (Wittum et al., 2010; Mollenkopf et al., 2012; Davis et al., 2015) may suggest the pos- 
sible emergence of $b l a_{\text {СТX-M-producing Escherichia coli }}$ within North America. The coexistence of 2 or more $\beta$-lactamases was detected in $44 \%$ of the MIC-confirmed ESC-R E. coli. This may explain how more than one resistance gene plays a critical role in the appearance of phenotypic resistance characteristics.

The PMQR genes were detected in 7 of 9 quinoloneresistant isolates, and to the best of our knowledge, this is the first detection of PMQR genes in dairy cattle in Canada. These qnr genes did not produce increased resistance to fluoroquinolones beyond the MIC breakpoints; however, in the presence of chromosomal mutations in DNA topoisomerase II, several-fold increases in MIC have been reported (Robicsek et al., 2006). The PMQR $B$ and $S$ were detected in $7 \beta$-lactamase producing isolates with 4 isolates harboring 2 or more $\beta$-lactamase resistance genes, usually $b l a_{\text {TEM }}$ and $b l a_{\mathrm{CMY}-2}$. The PMQR genes, especially qnrB19, are known to be frequently associated with other antimicrobial resistance genes especially $\beta$-lactamases, with colocation on the same plasmid and other mobile genetic elements (Cattoir et al., 2007).

In this study, calf age was associated with the fecal recovery of sESC-R E. coli. The increased frequency in neonates compared with calves at weaning agrees with other reports that prevalence is inversely related to age, with peaked prevalence commonly seen in the first 2 wk of life (Hoyle et al., 2004; Khachatryan et al., 2004; Donaldson et al., 2006; Edrington et al., 2012). A similar finding was observed in Salmonella enterica. This change in prevalence is attributed to age-associated changes in the commensal enteric microflora, which results in an intestinal microbiota that is more effective at excluding these bacteria (e.g., sESC-R E. coli and Salmonella enterica) from the intestinal microcosm (Berge et al., 2006a).

Use of ceftiofur for the treatment of respiratory diseases was protective against shedding of sESC-R $E$. coli; this may suggest the effect of ceftiofur use among the 8 herds may be due to the treatment of other nonrespiratory diseases such as reproductive diseases. Also, there is a possibility of use of other antimicrobials by the farms that were not using ceftiofur, which may be causing resistance selection. However, in the model without the influential covariate; the effect of this predictor was nonsignificant. Florfenicol use was associated with the fecal shedding of sESC-R E. coli; although both florfenicol (extra-label use) and ceftiofur (label use) are used for the treatment of respiratory disease in dairy cattle, the reason for the relationship is not clear. Interestingly, the association between the phenotypic florfenicol and third-generation cephalosporin resistance and the co-presence of $b l a_{\mathrm{CMY}-2}$ and flo- $R$ resistance genes on the same plasmid have been previously reported (Meunier et al., 2010).

All the farms sampled reportedly used ceftiofur in some fashion. However, calves from farms with regular ceftiofur use (monthly or more often) were more likely to shed sESC-R E. coli, suggesting that the use of this third-generation cephalosporin may drive resistance. Previous studies in different animal species have found that frequent use of antimicrobials is related to increased shedding of MDR bacteria (van den Bogaard and Stobberingh, 2000; Call et al., 2008) including dairy calves (Berge et al., 2006b). Although MDR E. coli has been reported in preweaned calves regardless of antimicrobial exposure (Khachatryan et al., 2004), the contribution of other factors apart from antimicrobial use such as unpasteurized nonsalable milk feeding has been reported (Pereira et al., 2014b).

In this study, unpasteurized nonsalable milk feeding was associated with the fecal recovery of sESC-R $E$. coli. Nonsalable milk feeding is a common practice in Canada (Vasseur et al., 2010). This practice has also been reported from other parts of the world including the United States (Pereira et al., 2014b), Sweden (Duse et al., 2013), and the United Kingdom (Brunton et al., 2014). Consistent with this study, the association between unpasteurized nonsalable milk feeding and increased shedding of MDR bacteria has also been reported (Berge et al., 2006a; Aust et al., 2013; Duse et al., 2015). Increased prevalence of MDR E. coli was reported to coincide with the period when calves are fed waste milk, suggesting that the fecal recovery in dairy calves may be diet related (Khachatryan et al., 2004). This feeding practice facilitates the exposure of dairy calves to antimicrobials via consumption, thus leading to possible antimicrobial selective pressure and resistance development (Randall et al., 2014).

The low discriminating power of the model used in predicting the association between the variables examined and fecal recovery of sESC-R E. coli is a major limitation in this study; with the model specificity of $40 \%$, there is a high probability of misclassification of dairy calves as shedders of ECS-R E. coli when in reality they are not. This is unsurprising considering the low number of dairy herds participating in this study. The association between the risk factors that were associated with fecal recovery of sESC-R E. coli will need to be further elucidated, and we believe this study can be a framework for a future, more robust, study.

This study has provided estimates of the distribution of ESC-R in dairy calves in New Brunswick, Canada. Using molecular epidemiologic techniques, it has provided information on the genes associated with the occurrence of resistance to ESC in dairy calves within 
this region. This study revealed a low frequency of Salmonella enterica in dairy calves. A high frequency of sESC-R E. coli could be found in calves when using a selective culture method for ESC enteric bacteria. The $B l a_{\mathrm{CMY}-2}$ and $b l a_{\mathrm{TEM}}$ were the prevalent $\beta$-lactamases found in ESC-R E. coli isolated from dairy calves. Calves' age, regular ceftiofur use on the farm, feeding of unpasteurized nonsalable milk, use of ceftiofur for treatment of respiratory diseases, and use of florfenicol were factors associated with fecal recovery of $E$. coli with reduced susceptibility to ESC. However, to our knowledge, this is the first report of the occurrence of $q n r B$ and $q n r S$ genes in $E$. coli isolated from dairy calves in Canada. We believe this will be relevant to the dairy farmers and veterinarians within this region for management purposes and epidemiologic understanding of factors influencing antimicrobial resistance.

\section{ACKNOWLEDGMENTS}

We are grateful to Cynthia Mitchell, Patty McKenna, and Matthew Saab (all from Atlantic Veterinary College, University of Prince Edward Island, Charlottetown Canada) for their laboratory support, to the dairy farmers and the veterinarians participating in the MILK 2020 project of New Brunswick, Canada, for their help and cooperation during this study. Thanks also go to Patrick Boerlin of Ontario Veterinary College, Canada, for supplying us with some of the positive controls used in this study.

\section{REFERENCES}

Abouzeed, Y. M., H. Hariharan, C. Poppe, and F. S. B. Kibenge. 2000 Characterization of Salmonella isolates from beef cattle, broiler chickens and human sources on Prince Edward Island. Comp. Immunol. Microbiol. Infect. Dis. 23:253-266. https://doi.org/10 1016/S0147-9571(99)00079-X.

Alexander, K. A., L. D. Warnick, and M. Wiedmann. 2009. Antimicrobial resistant Salmonella in dairy cattle in the United States. Vet. Res. Commun. 33:191-209. https://doi.org/10.1007/s11259 $-008-9170-7$.

Allen, K. J., and C. Poppe. 2002. Occurrence and characterization of resistance to extended-spectrum cephalosporins mediated bylactamase CMY-2 in Salmonella isolated from food-producing animals in Canada. Can. J. Vet. Res. 66:137-144.

Aust, V., K. Knappstein, H.-J. Kunz, H. Kaspar, J. Wallmann, and M. Kaske. 2013. Feeding untreated and pasteurized waste milk and bulk milk to calves: Effects on calf performance, health status and antibiotic resistance of faecal bacteria. J. Anim. Physiol. Anim. Nutr. (Berl.) 97:1091-1103. https://doi.org/10.1111/jpn.12019.

Berge, A. C. B., E. R. Atwill, and W. M. Sischo. 2005. Animal and farm influences on the dynamics of antibiotic resistance in faecal Escherichia coli in young dairy calves. Prev. Vet. Med. 69:25-38. https://doi.org/10.1016/j.prevetmed.2005.01.013.

Berge, A. C. B., D. A. Moore, and W. M. Sischo. 2006a. Prevalence and antimicrobial resistance patterns of Salmonella enterica in preweaned calves from dairies and calf ranches. Am. J. Vet. Res. 67:1580-1588. https://doi.org/10.2460/ajvr.67.9.1580.

Berge, A. C. B., D. A. Moore, and W. M. Sischo. 2006b. Field trial evaluating the influence of prophylactic and therapeutic antimi- crobial administration on antimicrobial resistance of fecal Escherichia coli in dairy calves. Appl. Environ. Microbiol. 72:3872-3878. https://doi.org/10.1128/AEM.02239-05.

Brunton, L. A., H. E. Reeves, L. C. Snow, and J. R. Jones. 2014 A longitudinal field trial assessing the impact of feeding waste milk containing antibiotic residues on the prevalence of ESBLproducing Escherichia coli in calves. Prev. Vet. Med. 117:403-412. https://doi.org/10.1016/j.prevetmed.2014.08.005.

Call, D. R., M. A. Davis, and A. A. Sawant. 2008. Antimicrobial resistance in beef and dairy cattle production. Anim. Health Res. Rev. 9:159-167. https://doi.org/10.1017/S1466252308001515.

Canadian Veterinary Medical Association. 2008. Antimicrobial Prudent Use Guidelines for Beef Cattle, Dairy Cattle, Poultry and Swine. Accessed Jul. 25, 2017. http://canadianveterinarians.net/ documents/cvma-antimicrobial-prudent-use-guidelines-2008-for -beef-dairy-poultry-swine.

Cantón, R., J. M. González-Alba, and J. C. Galán. 2012. CTX-M enzymes: Origin and diffusion. Front. Microbiol. 3. https://doi.org/ 10.3389/fmicb.2012.00110.

Cantón, R., M. I. Morosini, S. de la Maza, and E. G. G. De La Pedrosa. 2008. IRT and CMT $\beta$-lactamases and inhibitor resistance. Clin. Microbiol. Infect. 14:53-62.

Cattoir, V., L. Poirel, V. Rotimi, C.-J. Soussy, and P. Nordmann. 2007. Multiplex PCR for detection of plasmid-mediated quinolone resistance qnr genes in ESBL-producing enterobacterial isolates. J. Antimicrob. Chemother. 60:394-397. https://doi.org/10.1093/ $\mathrm{jac} / \mathrm{dkm} 204$.

Centers for Disease Control and Prevention. 2002. Salmonella surveillance: Annual summary, 2001. US Department of Health and Human Services, CDC, Atlanta, GA.

Centers for Disease Control and Prevention. 2016. Multistate Outbreak of Salmonella Montevideo and Salmonella Senftenberg infections linked to Wonderful pistachios. https://www.cdc.gov/ salmonella/montevideo-03-16/index.html.

CLSI (Clinical and Laboratory Standards Institute). 2002. Performance Standards for Antimicrobial Disk and Dilution Susceptibility Tests for Bacteria Isolated from Animals; Approved StandardSecond Edition. CLSI document M31-A2. Clinical and Laboratory Standards Institute, Wayne, PA.

CLSI (Clinical and Laboratory Standards Institute). 2015. Performance Standards for Antimicrobial Susceptibility Testing; Twenty-Fifth Informational Supplement. CLSI document M100-S25. Clinical and Laboratory Standards Institute, Wayne, PA.

Constable, P. D. 2004. Antimicrobial use in the treatment of calf diarrhea. J. Vet. Intern. Med. 18:8-17.

Cormier, A. C., G. Chalmers, T. A. McAllister, S. Cook, R. Zaheer, H. M. Scott, C. Booker, R. Read, and P. Boerlin. 2015. Extended-spectrum-cephalosporin resistance genes in Escherichia coli from beef cattle. Antimicrob. Agents Chemother. 60:1162-1163. https://doi.org/10.1128/AAC.02516-15.

Cummings, K. J., L. D. Rodriguez-Rivera, K. N. Norman, N. Ohta, and H. M. Scott. 2017. Identification of a plasmid-mediated quinolone resistance gene in Salmonella isolates from Texas dairy farm environmental samples. Zoonoses Public Health 64:305-307. https://doi.org/10.1111/zph.12318.

Dallenne, C., A. Da Costa, D. Decre, C. Favier, and G. Arlet. 2010 Development of a set of multiplex PCR assays for the detection of genes encoding important-lactamases in Enterobacteriaceae. J. Antimicrob. Chemother. 65:490-495. https://doi.org/10.1093/jac/ dkp498.

Daniels, J. B., D. R. Call, D. Hancock, W. M. Sischo, K. Baker, and T. E. Besser. 2009. Role of Ceftiofur in selection and dissemination of blaCMY-2-mediated cephalosporin resistance in Salmonella enterica and commensal Escherichia coli isolates from cattle. Appl. Environ. Microbiol. 75:3648-3655. https://doi.org/10.1128/AEM $.02435-08$.

Davis, M. A., W. M. Sischo, L. P. Jones, D. A. Moore, S. Ahmed, D. M. Short, and T. E. Besser. 2015. Recent emergence of Escherichia coli with cephalosporin resistance conferred by bla ${ }_{\text {CTX-M }}$ on Washington State dairy farms. Appl. Environ. Microbiol. 81:4403-4410. https://doi.org/10.1128/AEM.00463-15. 
de Verdier, K., A. Nyman, C. Greko, and B. Bengtsson. 2012. Antimicrobial resistance and virulence factors in Escherichia coli from Swedish dairy calves. Acta Vet. Scand. 54:2.

DeFrancesco, K. A., R. N. Cobbold, D. H. Rice, T. E. Besser, and D. D. Hancock. 2004. Antimicrobial resistance of commensal Escherichia coli from dairy cattle associated with recent multi-resistant salmonellosis outbreaks. Vet. Microbiol. 98:55-61. https://doi.org/ 10.1016/j.vetmic.2003.10.017.

Dohoo, I., W. Martin, and H. Stryhn. 2010. Veterinary Epidemiologic Research. 2nd ed. VER Inc., Charlottetown, Prince Edward Island, Canada.

Donaldson, S. C., B. A. Straley, N. V. Hegde, A. A. Sawant, C. DebRoy, and B. M. Jayarao. 2006. molecular epidemiology of ceftiofur-resistant Escherichia coli isolates from dairy calves. Appl. Environ. Microbiol. 72:3940-3948. https://doi.org/10.1128/AEM .02770-05.

Duse, A., K. P. Waller, U. Emanuelson, H. E. Unnerstad, Y. Persson, and B. Bengtsson. 2013. Farming practices in Sweden related to feeding milk and colostrum from cows treated with antimicrobials to dairy calves. Acta Vet. Scand. 55:49. https://doi.org/10.1186/ 1751-0147-55-49

Duse, A., K. P. Waller, U. Emanuelson, H. E. Unnerstad, Y. Persson, and B. Bengtsson. 2015. Risk factors for antimicrobial resistance in fecal Escherichia coli from preweaned dairy calves. J. Dairy Sci. 98:500-516. https://doi.org/10.3168/jds.2014-8432.

Edrington, T. S., R. L. Farrow, B. H. Carter, A. Islas, G. R. Hagevoort, T. R. Callaway, R. C. Anderson, and D. J. Nisbet. 2012. Age and diet effects on fecal populations and antibiotic resistance of a multi-drug resistant Escherichia coli in dairy calves. Agric. Food Anal. Bacteriol. 2:162-174.

Edrington, T. S., C. L. Schultz, K. M. Bischoff, T. R. Callaway, M. L. Looper, K. J. , Y. S. Genovese, J. L. Jung, R. C. McReynolds, Anderson, and D. J. Nisbet. 2004. Antimicrobial resistance and serotype prevalence of Salmonella isolated from dairy cattle in the Southwestern United States. Microb. Drug Resist. 10:51-56. https://doi.org/10.1089/107662904323047808.

European Food Safety Authority. 2012. Technical specifications on the harmonised monitoring and reporting of antimicrobial resistance in Salmonella, Campylobacter and indicator Escherichia coli and Enterococcus spp. bacteria transmitted through food. EFSA J. 10. https://doi.org/10.2903/j.efsa.2012.2742.

Fluckey, W. M., G. H. Loneragan, R. Warner, and M. M. Brashears. 2007. Antimicrobial drug resistance of Salmonella and Escherichia coli isolates from cattle feces, hides, and carcasses. J. Food Prot. 70:551-556.

Forward, K. R., K. M. Matheson, M. Hiltz, H. Musgrave, and C. Poppe. 2004. Recovery of cephalosporin resistant Escherichia coli and Salmonella from pork, beef and chicken marketed in Nova Scotia. Can. J. Infect. Dis. Med. Microbiol. 15:226-230.

Government of Canada. 2010. Canadian Integrated Program for Antimicrobial Resistance Surveillance (CIPARS) 2007. Public Health Agency of Canada, Guelph, ON, Canada.

Heider, L. C., J. A. Funk, A. E. Hoet, R. W. Meiring, W. A. Gebreyes, and T. E. Wittum. 2009a. Identification of Escherichia coli and Salmonella enterica organisms with reduced susceptibility to ceftriaxone from fecal samples of cows in dairy herds. Am. J. Vet. Res. 70:389-393. https://doi.org/10.2460/ajvr.70.3.389.

Heider, L. C., A. E. Hoet, T. E. Wittum, M. L. Khaitsa, B. C. Love, C. L. Huston, P. S. Morley, J. A. Funk, and W. A. Gebreyes. 2009b. Genetic and phenotypic characterization of the blaCMY gene from Escherichia coli and Salmonella enterica isolated from food-producing animals, humans, the environment, and retail meat. Foodborne Pathog. Dis. 6:1235-1240. https://doi.org/10 .1089/fpd.2009.0294.

Hordijk, J., A. B. Bosman, A. van Essen-Zandbergen, K. Veldman, C. Dierikx, J. A. Wagenaar, and D. Mevius. 2011. qnrB19 gene bracketed by IS26 on a 40-kilobase IncR plasmid from an Escherichia coli isolate from a veal calf. Antimicrob. Agents Chemother. 55:453-454. https://doi.org/10.1128/AAC.00866-10.

Hoyle, D. V.. D. J. Shaw, H. I. Knight, H. C. Davison, M. C. Pearce, J. C. Low, G. J. Gunn, and M. E. J. Woolhouse. 2004. Age-related decline in carriage of ampicillin-resistant Escherichia coli in young calves. Appl. Environ. Microbiol. 70:6927-6930. https://doi.org/10 .1128/AEM.70.11.6927-6930.2004.

Jackson, B. R., P. M. Griffin, D. Cole, K. A. Walsh, and S. J. Chai. 2013. Outbreak-associated Salmonella enterica serotypes and food commodities, United States, 1998-2008. Emerg. Infect. Dis. 19:1239-1244. https://doi.org/10.3201/eid1908.121511.

Khachatryan, A. R., D. D. Hancock, T. E. Besser, and D. R. Call. 2004. Role of calf-adapted Escherichia coli in maintenance of antimicrobial drug resistance in dairy calves. Appl. Environ. Microbiol. 70:752-757. https://doi.org/10.1128/AEM.70.2.752-757.2004.

Kirchner, M., H. Wearing, and C. Teale. 2011. Plasmid-mediated quinolone resistance gene detected in Escherichia coli from cattle. Vet. Microbiol. 148:434-435. https://doi.org/10.1016/j.vetmic.2010.08 .033 .

Kirk, J. H., C. A. Holmberg, and J. S. Jeffrey. 2002. Prevalence of Salmonella spp in selected birds captured on California dairies. J. Am. Vet. Med. Assoc. 220:359-362.

Kozak, G. K., P. Boerlin, N. Janecko, R. J. Reid-Smith, and C. Jardine. 2009. Antimicrobial resistance in Escherichia coli isolates from swine and wild small mammals in the proximity of swine farms and in natural environments in Ontario, Canada. Appl. Environ. Microbiol. 75:559-566. https://doi.org/10.1128/AEM.01821 $-08$

Li, X.-Z., M. Mehrotra, S. Ghimire, and L. Adewoye. 2007. $\beta$-Lactam resistance and $\beta$-lactamases in bacteria of animal origin. Vet. Microbiol. 121:197-214. https://doi.org/10.1016/j.vetmic.2007.01 .015 .

Magiorakos, A.-P., A. Srinivasan, R. B. Carey, Y. Carmeli, M. E. Falagas, C. G. Giske, S. Harbarth, J. F. Hindler, G. Kahlmeter, B. Olsson-Liljequist, D. L. Paterson, L. B. Rice, J. Stelling, M. J. Struelens, A. Vatopoulos, J. T. Weber, and D. L. Monnet. 2012. Multidrug-resistant, extensively drug-resistant and pandrug-resistant bacteria: An international expert proposal for interim standard definitions for acquired resistance. Clin. Microbiol. Infect. 18:268-281. https://doi.org/10.1111/j.1469-0691.2011.03570.x.

Martin, L. C., E. K. Weir, C. Poppe, R. J. Reid-Smith, and P. Boerlin. 2012. Characterization of blaCMY-2 plasmids in Salmonella and Escherichia coli isolates from food animals in Canada. Appl. Environ. Microbiol. 78:1285-1287. https://doi.org/10.1128/AEM .06498-11.

Mataseje, L. F., P. J. Baudry, G. G. Zhanel, D. W. Morck, R. R. Read, M. Louie, and M. R. Mulvey. 2010. Comparison of CMY-2 plasmids isolated from human, animal, and environmental Escherichia coli and Salmonella spp. from Canada. Diagn. Microbiol. Infect. Dis. 67:387-391. https://doi.org/10.1016/j.diagmicrobio.2010.02 .027 .

Megersa, B., A. Yacob, A. Regassa, F. Abuna, K. Asmare, and K. Amenu.. 2009. Prevalence and incidence rates of calf morbidity and mortality and associated risk factors in smallholder dairy farms in Hawassa, Southern Ethiopia. Ethiop. Vet. J. 13:59-68.

Meunier, D., E. Jouy, C. Lazizzera, B. Doublet, M. Kobisch, A Cloeckaert, and J.-Y. Madec. 2010. Plasmid-borne florfenicol and ceftiofur resistance encoded by the floR and blaCMY-2 genes in Escherichia coli isolates from diseased cattle in France. J. Med. Microbiol. 59:467-471. https://doi.org/10.1099/jmm.0.016162-0.

Mollenkopf, D. F., M. F. Weeman, J. B. Daniels, M. J. Abley, J. L. Mathews, W. A. Gebreyes, and T. E. Wittum. 2012. Variable within- and between-herd diversity of CTX-M cephalosporinasebearing Escherichia coli isolates from dairy cattle. Appl. Environ. Microbiol. 78:4552-4560. https://doi.org/10.1128/AEM.00373-12.

Mulvey, M. R., E. Susky, M. McCracken, D. W. Morck, and R. R. Read. 2009. Similar cefoxitin-resistance plasmids circulating in Escherichia coli from human and animal sources. Vet. Microbiol. 134:279-287. https://doi.org/10.1016/j.vetmic.2008.08.018.

Nordmann, P. 2005. Emergence of plasmid-mediated resistance to quinolones in Enterobacteriaceae. J. Antimicrob. Chemother. 56:463469. https://doi.org/10.1093/jac/dki245.

Pereira, R. V., J. D. Siler, R. C. Bicalho, and L. D. Warnick. 2014. Multiresidue screening of milk withheld for sale at dairy farms in 
central New York State. J. Dairy Sci. 97:1513-1519. https://doi .org/10.3168/jds.2013-7421.

Pereira, R. V., J. D. Siler, J. C. Ng, M. A. Davis, and L. D. Warnick. 2014a. Effect of preweaned dairy calf housing system on antimicrobial resistance in commensal Escherichia coli. J. Dairy Sci. 97:7633-7643. https://doi.org/10.3168/jds.2014-8588.

Pereira, R. V. V., J. D. Siler, R. C. Bicalho, and L. D. Warnick. 2014b. In vivo selection of resistant $E$. coli after ingestion of milk with added drug residues. PLoS One 9:e115223. https://doi.org/ 10.1371/journal.pone.0115223.

Philippczik, G., J. Fehrenbach, B. Steinbrückner, K. Potthoff, A. Spyridonidis, A. Leindemann, M. Kist, and T. M. Bauer. 1999. Nosocomial diarrhea caused by Salmonella Derby infection in two patients on chemotherapy. Clin. Microbiol. Infect. 5:586-588. https://do .org/10.1111/j.1469-0691.1999.tb00442.x.

Pitout, J. D., N. D. Hanson, D. L. Church, and K. B. Laupland. 2004a. Population-based laboratory surveillance for Escherichia coli-producing extended-spectrum $\beta$-lactamases: Importance of community isolates with blaCTX-M genes. Clin. Infect. Dis. 38:1736-1741.

Pitout, J. D. D., A. Hossain, and N. D. Hanson. 2004b. Phenotypic and molecular detection of CTX-M-beta-lactamases produced by Escherichia coli and Klebsiella spp. J. Clin. Microbiol. 42:57155721. https://doi.org/10.1128/JCM.42.12.5715-5721.2004.

Public Health Agency of Canada. 2014. Antimicrobial Resistance and Use in Canada: A Federal Framework for Action. Government of Canada, Ottawa, Canada.

Rabsch, W. 2002. Salmonella enterica serotype Typhimurium and its host-adapted variants. Infect. Immun. 70:2249-2255. https://doi .org/10.1128/IAI.70.5.2249-2255.2002.

Randall, L., K. Heinrich, R. Horton, L. Brunton, M. Sharman, V. Bailey-Horne, M. Sharma, I. McLaren, N. Coldham, C. Teale, and J. Jones. 2014. Detection of antibiotic residues and association of cefquinome residues with the occurrence of Extended-Spectrum $\beta$-Lactamase (ESBL)-producing bacteria in waste milk samples from dairy farms in England and Wales in 2011. Res. Vet. Sci. 96:15-24. https://doi.org/10.1016/j.rvsc.2013.10.009.

Robicsek, A., J. Strahilevitz, D. F. Sahm, G. A. Jacoby, and D. C. Hooper. 2006. qnr prevalence in ceftazidime-resistant Enterobacteriaceae isolates from the United States. Antimicrob. Agents Chemother. 50:2872-2874. https://doi.org/10.1128/AAC.01647-05.

Saini, V., J. T. McClure, D. T. Scholl, T. J. DeVries, and H. W. Barkema. 2013. Herd-level relationship between antimicrobial use and presence or absence of antimicrobial resistance in gram-negative bovine mastitis pathogens on Canadian dairy farms. J. Dairy Sci. 96:4965-4976. https://doi.org/10.3168/jds.2012-5713.

Sawant, A. A., N. V. Hegde, B. A. Straley, S. C. Donaldson, B. C. Love, S. J. Knabel, and B. M. Jayarao. 2007. Antimicrobial-resistant enteric bacteria from dairy cattle. Appl. Environ. Microbiol. 73:156-163. https://doi.org/10.1128/AEM.01551-06.

Schmidt, J. W., D. Griffin, L. A. Kuehn, and D. M. Brichta-Harhay 2013. Influence of therapeutic ceftiofur treatments of feedlot cattle on fecal and hide prevalences of commensal Escherichia coli resistant to expanded-spectrum cephalosporins, and molecular characterization of resistant isolates. Appl. Environ. Microbiol. 79:22732283. https://doi.org/10.1128/AEM.03592-12.
Seiffert, S. N., M. Hilty, V. Perreten, and A. Endimiani. 2013. Extended-spectrum cephalosporin-resistant gram-negative organisms in livestock: An emerging problem for human health? Drug Resist. Updat. 16:22-45. https://doi.org/10.1016/j.drup.2012.12.001.

Singh, K., K. A. Mangold, K. Wyant, D. M. Schora, B. Voss, K. L. Kaul, M. K. Hayden, V. Chundi, and L. R. Peterson. 2012. Rectal screening for Klebsiella pneumoniae carbapenemases: Comparison of real-time PCR and culture using two selective screening agar plates. J. Clin. Microbiol. 50:2596-2600. https://doi.org/10.1128/ JCM.00654-12.

Sorensen, O., M. McFall, and K. Manninen. 2003. Prevalence of Salmonella in dairy herds in Alberta. Can. Vet. J. 44:230-231.

Tragesser, L. A., T. E. Wittum, J. A. Funk, P. L. Winokur, and P. J. Rajala-Schultz. 2006. Association between ceftiofur use and isolation of Escherichia coli with reduced susceptibility to ceftriaxone from fecal samples of dairy cows. Am. J. Vet. Res. 67:1696-1700. https://doi.org/10.2460/ajvr.67.10.1696.

van den Bogaard, A. E., and E. E. Stobberingh. 2000. Epidemiology of resistance to antibiotics. Int. J. Antimicrob. Agents 14:327-335. https://doi.org/10.1016/S0924-8579(00)00145-X.

Vasseur, E., F. Borderas, R. I. Cue, D. Lefebvre, D. Pellerin, J. Rushen, K. M. Wade, and A. M. de Passille. 2010. A survey of dairy calf management practices in Canada that affect animal welfare. J. Dairy Sci. 93. https://doi.org/10.3168/jds.2009-2429.

Veterinary Drugs Directorate, Health Canada. 2009. Categorization of antimicrobial drugs based on their importance in human medicine (Table 23). Accessed Jul. 25, 2017. http://www.hc-sc.gc.ca/dhp -mps/vet/antimicrob/amr_ram_hum-med-rev-eng.php.

Wang, H. H., M. Manuzon, M. Lehman, K. Wan, H. Luo, T. E. Wittum, A. Yousef, and L. O. Bakaletz. 2006. Food commensal microbes as a potentially important avenue in transmitting antibiotic resistance genes. FEMS Microbiol. Lett. 254:226. https://doi.org/ 10.1111/j.1574-6968.2005.00030.x.

Wells, S. J., P. J. Fedorka-Cray, D. A. Dargatz, K. Ferris, and A. Green. 2001. Fecal shedding of Salmonella spp. by dairy cows on farm and at cull cow markets. J. Food Prot. 64:3-11.

Winokur, P. L., D. L. Vonstein, L. J. Hoffman, E. K. Uhlenhopp, and G. V. Doern. 2001. Evidence for transfer of CMY-2 AmpClactamase plasmids between Escherichia coli and Salmonella isolates from food animals and humans. Antimicrob. Agents Chemother. 45:2716-2722. https://doi.org/10.1128/AAC.45.10.2716 -2722.2001 .

Wittum, T. E., D. F. Mollenkopf, J. B. Daniels, A. E. Parkinson, J. L. Mathews, P. R. Fry, M. J. Abley, and W. A. Gebreyes. 2010. CTXM-type extended-spectrum $\beta$-lactamases present in Escherichia coli from the feces of cattle in Ohio, United States. Foodborne Pathog. Dis. 7:1575-1579. https://doi.org/10.1089/fpd.2010.0615.

World Health Organization. 2007. Critically important antimicrobials for human medicine: categorization for the development of risk management strategies to contain antimicrobial resistance due to non-human antimicrobial use. Report of the second WHO Expert Meeting, Copenhagen, 29-31 May 2007 Geneva: The Organization. Accessed Sep. 20, 2017. http://www.who.int/foodborne_disease/ resistance/antimicrobials_human.pdf. 